\title{
Preparation and Characterization of Subsurface Silver Particulate Films on Polymer Blends of Polystyrene/Poly (2-vinylpyridine)/Poly(vinylpyrollidone)/ Poly(4-vinylpyridine)
}

\author{
Pratima Parashar Pandey* \\ Department of Materials Science, Mangalore University, Mangalagangotri, India \\ Email: pratimaparashara@rediffmail.com
}

Received 2 January 2015; accepted 19 January 2015; published 26 January 2015

Copyright (C) 2015 by author and Scientific Research Publishing Inc.

This work is licensed under the Creative Commons Attribution International License (CC BY). http://creativecommons.org/licenses/by/4.0/

\section{(c) (i) Open Access}

\section{Abstract}

Silver particulate thin films on softened polymer blends of Polystyrene (PS)/Poly(2-vinyl pyridine) (P2VP), PS/Poly(4-vinylpyridine) (P4VP), and Poly(vinylpyrollidone) (PVP)/P4VP at a rate of 0.4 $\mathrm{nm} / \mathrm{s}$ held at a temperature of $457 \mathrm{~K}$ in vacuum of $8 \times 10^{-6}$ Torr by evaporation are deposited. These silver films were characterized by their electrical behavior, optical properties and Scanning electron microscopy (SEM). Silver films deposited on softened PS, and PVP give rise to a very high room temperature resistance approaching that of the substrate resistance due to the formation of a highly agglomerated structure. On the other hand, silver films on softened P2VP and P4VP give rise to a room temperature resistance in the range of tens to a few hundred $M \Omega / \square$ which is desirable for device applications. Silver films on the composites of PS/P2VP, PS/P4VP and PVP/P4VP show resistances at room temperature. The optical and plasmonic response of Ag nanoparticles onto thin layers of blends shows encapsulation of nanoparticles. The electrical properties and SEM of silver nanoparticles on the thin layers of polymer blends indicate the formation of much smaller, narrower dispersion and wide size distribution.

\section{Keywords}

Nanoparticles, Polymer Blends, Thin Films, Vapor Deposition, Electrical Properties, Optical Properties, SEM

\footnotetext{
*Present address: Applied Sciences CET, AHL, IILM, G. Noida, India.

How to cite this paper: Pandey, P.P. (2015) Preparation and Characterization of Subsurface Silver Particulate Films on Polymer Blends of Polystyrene/Poly(2-vinylpyridine)/Poly(vinylpyrollidone)/Poly(4-vinylpyridine). Soft Nanoscience Letters, 5, 3-11. http://dx.doi.org/10.4236/snl.2015.51002
} 


\section{Introduction}

Polymer/inorganic nanocomposites have been of great interest in recent years, not only for the novel properties of the nanocomposite materials but also for the continuously growing demand for the miniaturization of electronics components, optical detectors, chemical and biochemical sensors and devices [1].

Polymer matrices have been frequently used as particle stabilizers in synthesis of metal colloids since these prevent agglomeration of the particles. Within the past decade, incorporating silver nanoparticle into a polymer matrix is more interesting because the resulting nanocomposites exhibit applications in catalysis, drug delivery, wound dressing, antimicrobial activity and optical information storage [2]-[8].

It is difficult to disperse silver nanoparticle homogeneously into a polymer matrix by ex situ methods because of easy agglomeration of nanoparticles [9]. At present, it is possible to obtain nanoparticles of different shape and size in nano structured polymeric environment where various polymeric systems and different approaches can be used. Numerous methods used toxic and potentially hazardous reactants. Increasing environmental concerns is resulted in an attempt to adopt eco-friendly methods.

One of the simplest and eco-friendly techniques to form such particulate structures, which are generally known as island or discontinuous metal films, is through vacuum evaporation of metal on to a dielectric substrate by stopping the deposition at a very early stage. The temporal instability exhibited by island films even in vacuum is attributed to mobility of islands followed by coalescence. Further, these films get oxidized when they are exposed to atmosphere. The oxidation of islands causes an irreversible increase in electrical resistance [10]. An interesting sub-surface particulate structure formation was reported when certain inorganic materials are deposited on to softened polymer substrates [11]-[14]. The morphology and formation of such structures depend on thermodynamic as well as deposition parameters [13] [14]. The use of softened polymer substrates provides the unique possibility of easily controlling the viscosity of the substrate to form a subsurface discontinuous silver particulate films. The morphology of sub-surface particulate structures also depends upon polymer metal interaction [14][17]. The reported method is evaporation of silver on polymer substrate at high temperature and in vacuum of the order of $10^{-6}$ Torr. The ability to precisely tailor and optimize the nanocomposite structure creates opportunities for a wide range of applications.

Blending of polymers provide the requisite matrix so that the property of PS and PVP can be combined with P2VP and P4VP. By varying the blend compositions suitable polymer composite exhibited the desired results. The subsurface silver films could be deposited on PS/P2VP (50:50), PS/P4VP (50:50, 25:75) and PVP/P4VP (50:50) which yield room temperature resistances in the range of a few tens to a few hundred $\mathrm{M} /$ desirable for device applications.

\section{Experimental}

Poly(4-vinyl pyridine), Poly(2-vinylpyridine) and Poly(vinylpyrollidone) used in this study, were procured from Sigma-Aldrich Chemicals Pvt. Ltd and Polystyrene from Alfa-Aesar (A Johnson Mathley Company) respectively. The molecular weights of P4VP, P2VP and PS are 60,000, 37,500 and 100,000, respectively. The structure of P4VP, P2VP, PS and PVP are (a), (b), (c) and (d) respectively, as follows:
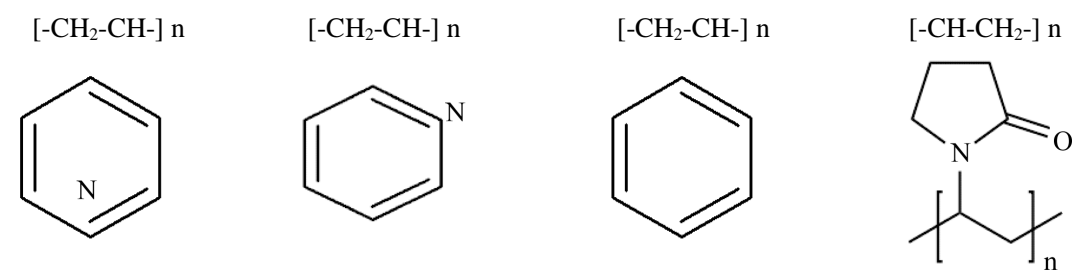

Polymer blends (PS/P2VP/P4VP) were prepared through solution blending by mixing in a common solvent, Dimethylformamide (DMF). Blends of PS/P4VP with different compositions \{PS (w)/P4VP (w) = 0:100; 25:75, 50:50; 75:25; 100:0 $\}$ were prepared. $1 \mathrm{~g}$ of the total polymers at different ratios was dissolved in $20 \mathrm{ml}$ of DMF at room temperature. Composite of PS/P2VP with different compositions $\{\mathrm{PS}(\mathrm{w}) / \mathrm{P} 2 \mathrm{VP}(\mathrm{w})=0: 100 ; 50: 50 ; 100: 0\}$ were prepared. An amount of $0.5 \mathrm{~g}$ of the total polymers at different ratios, were dissolved in $5 \mathrm{ml}$ of DMF at room temperature. 
Polymer blends of PVP/P4VP were prepared through solution blending by mixing in a common solvent, water. Blends of PVP/P4VP with different compositions $\{$ PVP $(w) / P 4 V P(w)=0: 100 ; 50: 50 ; 100: 0\}$ were prepared. $1 \mathrm{~g}$ of the total polymers at different ratios was dissolved in $20 \mathrm{ml}$ double distilled water at room temperature.

Thin films of homopolymers and their composite of approximately $5 \mu \mathrm{m}$ thickness were solution cast on a glass slide pre-coated with silver contacts with a gap of $1 \mathrm{~cm} \times 1 \mathrm{~cm}$ for electrical studies. Silver films of various thicknesses were deposited on these substrates held at $457 \mathrm{~K}$ in a vacuum better than $8 \times 10^{-6}$ Torr. The glass transition temperature of P4VP, P2VP, PVP and PS are 410, 357, 379 and $373 \mathrm{~K}$, respectively. Therefore, polymer substrates are softened at $457 \mathrm{~K}$ and sufficient fluidity is ensured. A chromel-alumel thermocouple was used to measure the substrate temperature by clamping it to the substrate surface holding the film. Source to substrate distance was maintained at $20 \mathrm{~cm}$. A Telemark quartz crystal monitor (Model 850) was used to measure the deposition rate, as well as the overall film thickness. The deposition rate used was $0.4 \mathrm{~nm} / \mathrm{s}$ for all the films. Resistance measurements were carried out in-situ, using a Keithley electrometer model 617. The films were annealed at the deposition temperature for 1 hour before cooling them to room temperature.

Optical absorption spectra of the silver particulate films were obtained on a Shimadzu Uv-Vis-NIR spectrophotometer model SHIMADZU UV 3101 PC.

Scanning electron microscopy (SEM) measurements were carried out on a Leica Cambridge Instruments Stereoscan 440 SEM with image processing software.

\section{Result and Discussion}

We need the compatibility of blends at higher temperature to ensure formation of polymer composite above their glass transition temperature. Blending of polymers provide the requisite matrix so that the property of PS and PVP can be combined with P2VP and P4VP. By varying the blend compositions suitable polymer composite exhibited the desired results. The compatibility of the solution cast PS/P4VP and PS/P2VP blends was studied by using Dilute Solution Viscometry (DSV), Differential Scanning Calorimetry (DSC), Fourier transformation infrared spectroscopy (FTIR) and Scanning Electron Microscopy (SEM). The blends were found to be compatible at higher temperature [15] [18]. The subsurface silver films could be deposited on PS/P2VP (50:50), PS/P4VP (50:50, 25:75) and PVP/P4VP (50:50) which yield room temperature resistances in the range of a few tens to a few hundred M/ desirable for device applications.

In-situ electrical resistance measurements yield about structure of discontinuous silver particulate films deposited on polymer composites. Table 1 presents the resistance data for the silver films of various thickness deposited on different polymer blend substrates held at $457 \mathrm{~K}$ with a rate of $0.4 \mathrm{~nm} / \mathrm{s}$. It is clear that room temperature resistance of silver films deposited at $457 \mathrm{~K}$ is very high for PS and PVP approaching that of the substrate resistances value where as a few mega ohms resistances are measured for P2VP and P4VP composites. This shows silver films are particulate in nature hence amounts for high resistances even for high thickness up to $200 \mathrm{~nm}$. It may be due to silver deposited is dispersed in softened polymer composites and formed a subsurface particulate within the polymer matrix [14]. Negative temperature coefficient of resistances (TCR) was observed for all the films which is the characteristic of particulate film. Negative TCR is the indication of highly agglomerated subsurface structure as observed for PS and PVP for any thickness and PS/P4VP (75:25) for $50 \mathrm{~nm}$. But the magnitude of TCR is small for higher thickness films on PS/P4VP (75:25) for $150 \mathrm{~nm}$, PS/P2VP (50:50) for 100, 150 and $200 \mathrm{~nm}$ and PVP/P4VP for $86 \mathrm{~nm}$ thick films. TCR for all such films was found to be zero at lower temperatures.

The dc resistances of the particulate film are exponentially dependent on inter-cluster separation or tunnelling length. Therefore, observed high resistances were attributed to very large inter-spacing and bigger cluster sizes for PS which is reduced with the decreasing content of PS in the blend and increasing thickness of film. Overall resistance of film deposited on composites decreases with increase in thickness of silver films. Similar behaviour is reported that the electrical conductivity of composites is increased with high silver loading (30\% - 80\%) [19]. Pyridine ring with Nitrogen atom in the structure of P2VP and P4VP causes the change in the morphology of these films as compared to PS and PVP.

Figures 1-3 show the SEM pictures of silver films deposited on PS/P2VP/P4VP composites. It is clear from Figures 1[1(a), 2(a), 3(a)] that size and inter-spacing in case of individual polymer for thickness of $100 \mathrm{~nm}$ is 109, 68 and $139 \mathrm{~nm}$ for P2VP, P4VP and PS, respectively. These are in agreement with their electrical properties. Blending of polymers resulted in a requisite polymer matrix which shows modification in the morphology 
Table 1. Resistance data for silver films deposited on polymers blends held at $457 \mathrm{~K}$ at the rate of $0.4 \mathrm{~nm} / \mathrm{s}$.

\begin{tabular}{|c|c|c|c|c|c|c|c|c|c|c|c|c|c|c|c|c|}
\hline \multirow{4}{*}{$\begin{array}{l}\text { Silver } \\
\text { film } \\
\text { thickness } \\
\text { (in } \mathrm{nm} \text { ) }\end{array}$} & \multicolumn{16}{|c|}{ Resistances (M $\Omega / \square)$} \\
\hline & \multicolumn{2}{|c|}{ On PS } & \multicolumn{2}{|c|}{$\begin{array}{c}\text { On } \\
\text { PS/P2VP } \\
\text { 50:50 }\end{array}$} & \multicolumn{2}{|c|}{$\begin{array}{l}\text { On } \\
\text { P2VP }\end{array}$} & \multicolumn{2}{|c|}{$\begin{array}{l}\text { On } \\
\text { PVP }\end{array}$} & \multicolumn{2}{|c|}{$\begin{array}{c}\text { On } \\
\text { PVP/P4VP }\end{array}$} & \multicolumn{2}{|c|}{$\begin{array}{c}\text { On } \\
\text { PS/P4VP }\end{array}$} & \multicolumn{2}{|c|}{$\begin{array}{c}\text { On } \\
\text { PS/P4VP } \\
50 \cdot 50\end{array}$} & $\begin{array}{c}\text { On } \\
\text { PS/P4VP } \\
75 \cdot 25\end{array}$ & $\begin{array}{c}\text { On } \\
\text { P4VP }\end{array}$ \\
\hline & & $57 \mathrm{~K}$ & 45 & & 45 & $7 \mathrm{~K}$ & & $57 \mathrm{~K}$ & & $7 \mathrm{~K}$ & & $7 \mathrm{~K}$ & & $57 \mathrm{~K}$ & $457 \mathrm{~K}$ & $457 \mathrm{~K}$ \\
\hline & & $00 \mathrm{~K}$ & 30 & & 30 & $\mathrm{~K}$ & & $00 \mathrm{~K}$ & & $0 \mathrm{~K}$ & & $0 \mathrm{~K}$ & & $00 \mathrm{~K}$ & $300 \mathrm{~K}$ & $300 \mathrm{~K}$ \\
\hline 50 & 302 & $>1000$ & 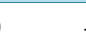 & & 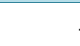 & - & 15 & $>1000$ & & & 6.2 & 47.1 & 15.9 & 159.4 & $214>1000$ & $1.9 \quad 27.1$ \\
\hline 85 & & - & & & & - & & & 7.2 & 113 & 3.2 & 14.2 & & & - & - \\
\hline 95 & & - & & & & - & & - & & - & & - & 2.9 & 30.1 & - & - \\
\hline 100 & & - & 47 & 115 & 12.28 & 32.6 & & - & & - & & - & & - & - & - \\
\hline 150 & 54 & $>1000$ & 11.5 & 42 & 9.73 & 26.1 & & - & & - & & - & & - & 14.8 & 248.9 \\
\hline 200 & & - & 10.35 & 30.1 & & - & & - & & - & & - & & & - & - \\
\hline
\end{tabular}

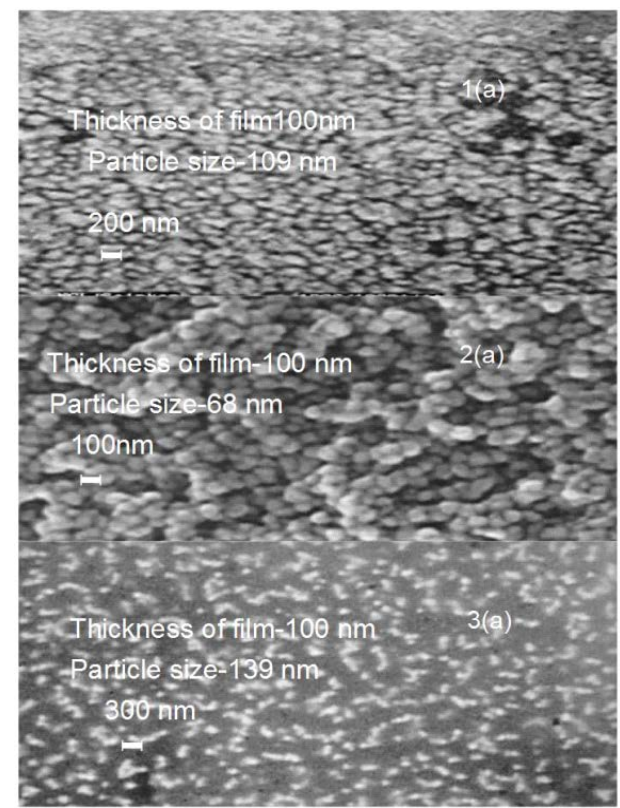

Figure 1. SEM of silver films deposited P2VP, P4VP and PS for $100 \mathrm{~nm}$.

of films and hence improvement in tunnelling length in the film deposited on polymer composites. Blending of P2VP and P4VP with PS is expected to provide a polymer matrix where the size of silver clusters and intercluster separation can be modified because of dispersion, size distribution and impregnation depth results from the natures of polymeric hosts [20] [21].

Figure 2 clearly shows the particle sizes and inter-separation for PS/P4VP composites. The particle size for 50 nm films [2(a), 2(b)] on P4VP and PS are 58 and 92 nm, respectively. SEM 3a, 4a show the particle size distribution for 50 and $95 \mathrm{~nm}$ thick silver films deposited on PS/P4VP, 50:50. The data fit into a log normal distribution for both the cases. The average size, a and geometric standard deviation, $\sigma_{\mathrm{a}}$ are $79.4 \mathrm{~nm}$ and 1.2, respectively for the $50 \mathrm{~nm}$ film whereas the corresponding values for the $95 \mathrm{~nm}$ film are 95.4 and 1.4. A closer look at the morphology of silver nanoparticles deposited on PS/P4VP, 50:50 in SEM. 3a \& 4a, clearly show that particle size increases with the amount of silver deposited. The shape of the nanoparticles changes from near spherical particles to irregular ellipsoidal particles. The average size of the particle increases from 79.4 to $95.4 \mathrm{~nm}$ and the size distribution expands from 50 - $110 \mathrm{~nm}$ to 60 - $160 \mathrm{~nm}$ which results in improvement of tunnelling effect in PS/P4VP, 50:50 [21]. It is evident that increase in size distribution decreases the inter-separation of silver clusters in this blend. This fact may be regarded as a consequence of the size as well as inter-separation evolution of nanoparticles during the ongoing deposition process. SEM pictures 5a \& 6a show the particle size distribution for $50 \mathrm{~nm}$ and 


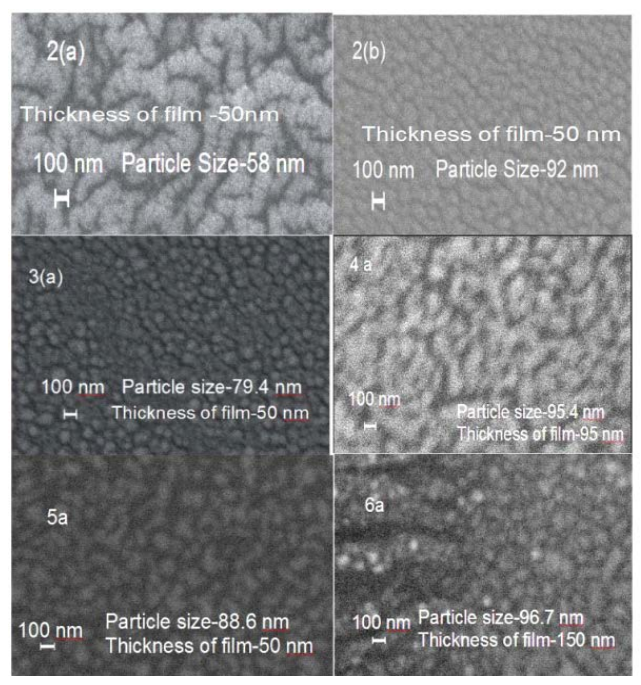

Figure 2. SEM of silver films on PS/P4VP composites for various thicknesses.

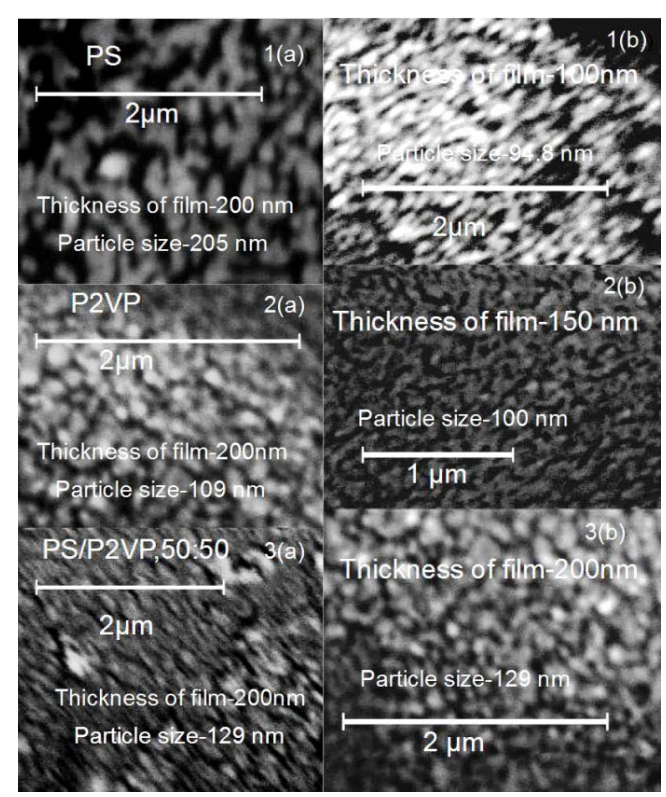

Figure 3. SEM of silver films on PS/P2VP composites for various thicknesses.

$150 \mathrm{~nm}$ thickness films deposited on PS/P4VP, 75:25. The average size, a and geometric standard deviation, $\sigma_{\mathrm{a}}$ are $88.6 \mathrm{~nm}$ and 8.5 for the $50 \mathrm{~nm}$ film and 96.7 and 4 for $150 \mathrm{~nm}$ film, respectively. It is evident from the figure that distribution of size increased from 50 to $120 \mathrm{~nm}$ to 60 to $140 \mathrm{~nm}$. Such dispersion of silver nanoparticle within the PS/P4VP, 75:25 leads to better electrical behaviour [21]. Such electric behaviour is not observed even for $300 \mathrm{~nm}$ silver particulate film on PS [22]. Hence, silver particulate films on PS/P4VP, 75/25 at low volume fraction of silver consist of isolated and widely dispersed nanoparticles. But systematic and controlled increase of silver volume in the PS/P4VP, 75:25 matrixes produced interesting result [21].

Figure 3 indicates modification in silver particulate films deposited on PS/P2VP composites. The particle sizes measured from respective SEM pictures [1(a), 2(a), 3(a)] fit into a log normal distribution for all the cases. The average size, a and geometric standard deviation, $\sigma_{\mathrm{a}}$ are $205 \mathrm{~nm}$ and 4; $109 \mathrm{~nm}$ and 9, $129 \mathrm{~nm}$ and 3, respectively, for silver films on PS, P2VP and their blend (50:50). The size distribution indicates that the particle size varies from 100 to $400 \mathrm{~nm}, 60$ to $180 \mathrm{~nm}$ and 60 to $200 \mathrm{~nm}$ for silver films on PS, P2VP and their blend (50:50). It is clear 
from the figure that the size and inter-separation of silver clusters is wide in PS whereas size as well as interseparation is less in P2VP [14]. As a result, PS do not show the desired electrical conductivity [22]. Blending of P2VP with PS modifies size, size distribution and inter-separation of silver particles on their blend PS/P2VP, 50:50 which results in improvement of tunnelling effect in the blend and the blend shows desired electrical behaviour [15]. SEM pictures [1(b), 2(b), 3(b)] show the particle size distribution for 100, 150 and $200 \mathrm{~nm}$ thickness films deposited on PS/P2VP, 50:50. The average size, a and geometric standard deviation, $\sigma_{\mathrm{a}}$ are $94.8 \mathrm{~nm}, 1.5$ and $100 \mathrm{~nm}, 5$ and $129 \mathrm{~nm}, 3$ for the 100,150 and $200 \mathrm{~nm}$ film, respectively. It is evident from the figure that size distribution varied from 55 - 125, 65 - 135 to 70 - $200 \mathrm{~nm}$ for the 100, 150 and $200 \mathrm{~nm}$ films, respectively. Such dispersion of silver nanoparticle within the PS/P2VP, 50:50 leads to better electrical behaviour [15]. This electric behaviour is not observed even for $300 \mathrm{~nm}$ silver particulate films on PS [22]. Hence, silver particulate films on PS/P2VP, 50:50 at low volume fraction of silver consist of isolated and widely dispersed nanoparticles. But systematic and controlled increase of silver volume in the blend matrixes has shown increase in the size of silver clusters [15].

Silver nanocomposite film exhibits characteristic UV absorbance spectrum at a wavelength of $430 \mathrm{~nm}$, due to the surface plasmon resonance of nanosized silver [23]-[26]. These nanoparticles exhibit unique optical properties originating from the characteristic surface plasmon by the collective motion of conduction electrons [25] [26].

Thus, the formation of silver nanoparticles can also be confirmed by UV/VIS absorption spectrum of composite films [27]. Spectral position, half width and intensity of the plasmon resonance strongly depend on the particle size, shape and the dielectric properties of the particle material and the surrounding medium [27]. Thus, the type of metal and the surrounding dielectric medium play a significant role in the excitation of particle plasmon resonance (PPR). The sensitivity of PPR frequency to small variations of these parameters can be exploited in various applications [28]. The differences in dispersion, size distribution and impregnation depth results from the differing natures of the polymeric hosts [16].

Figure 4 shows the optical absorption spectra recorded for $100 \mathrm{~nm}$ silver films deposited on polymeric blends held at $457 \mathrm{~K}$ at the deposition rate of $0.4 \mathrm{~nm} / \mathrm{s}$. Silver particles embedded in PS/P2VP blends observed a shift of the resonance position to higher wavelength (red shift) which were correlated with changes of particle sizes and inter-separation in silver clusters. It is clearly seen (Figure 4) that the plasmon resonance peak shifts towards the longer wavelength side for the PS/P2VP, 50:50 (435) as compared to pure polystyrene (429 nm). Also, there is increase in intensity of absorbing peaks which signify the decrease of particles size with the incorporation of P2VP into PS [24]. P2VP exhibits two peaks (441, $606 \mathrm{~nm}$ ). It is interesting to note that PS/P2VP, 50:50 also shows an additional absorption band at higher wavelength $(616 \mathrm{~nm})$. The possible explanation is that silver nanoparticles are in a highly aggregated state leading to coupling of the plasmon vibrations between neighbouring particles [29]. Similar results were found for silver particulate films of 150 and $200 \mathrm{~nm}$ films on PS/P2VP 50:50 blends. The

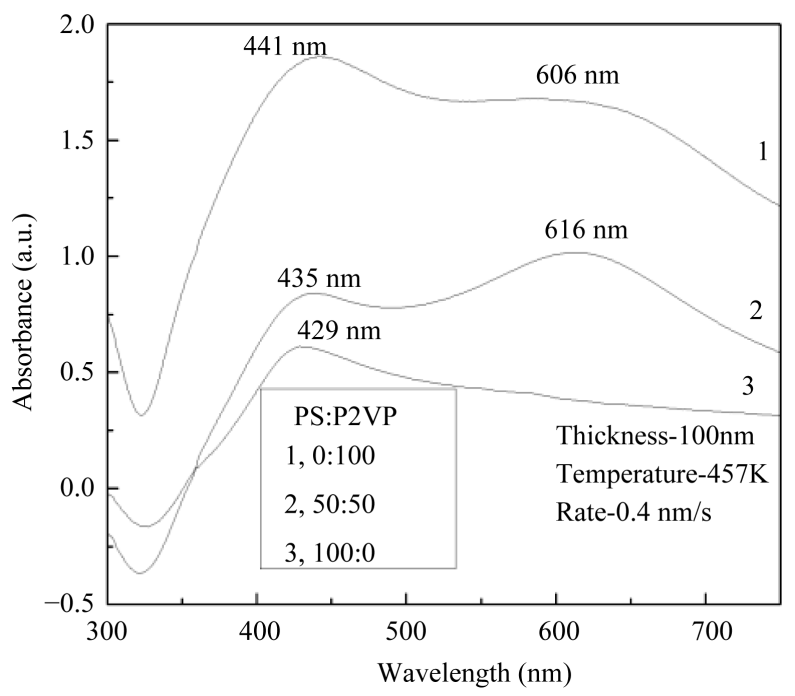

Figure 4. Optical absorption spectra for $100 \mathrm{~nm}$ silver particulate film deposited on PS/P2VP blends. 
increase in particle size of silver nanoparticles are due to increasing thickness of silver particulate films on the blends (Figure 3) [30].

Figure 5 shows the optical absorption spectra recorded for $50 \mathrm{~nm}$ silver films deposited on polymeric blends held at $457 \mathrm{~K}$ at the deposition rate of $0.4 \mathrm{~nm} / \mathrm{s}$. For silver particles embedded in PS/P4VP blends, a shift of the resonance position to higher wavelength (red shift) was found, which were correlated with changes of particle sizes and inter-separation in silver clusters. It is clearly seen (Figure 5) that the plasmon resonance peak shifts towards the longer wavelength side as compared to pure polystyrene $(485.5 \mathrm{~nm})$ with increasing percentage of $\mathrm{P} 4 \mathrm{VP}$ in the blends. Also, there is increase in intensity of absorbing peaks which signify the decrease of particles size with the incorporation of P4VP into PS [25].

Figure 6 shows the optical absorption spectra recorded for 52 \& $86 \mathrm{~nm}$ silver films deposited on polymeric blends of PVP/P4VP held at $457 \mathrm{~K}$ at the deposition rate of $0.4 \mathrm{~nm} / \mathrm{s}$. Silver particles embedded in PVP/P4VP blends observed a shift of the resonance position to higher wavelength (red shift) which were correlated with changes of particle sizes and inter-separation in silver clusters. It is clearly seen (Figure 6) that the plasmon resonance peak shifts towards the longer wavelength side for the PVP/P4VP, 50:50 (653) as compared to pure PVP

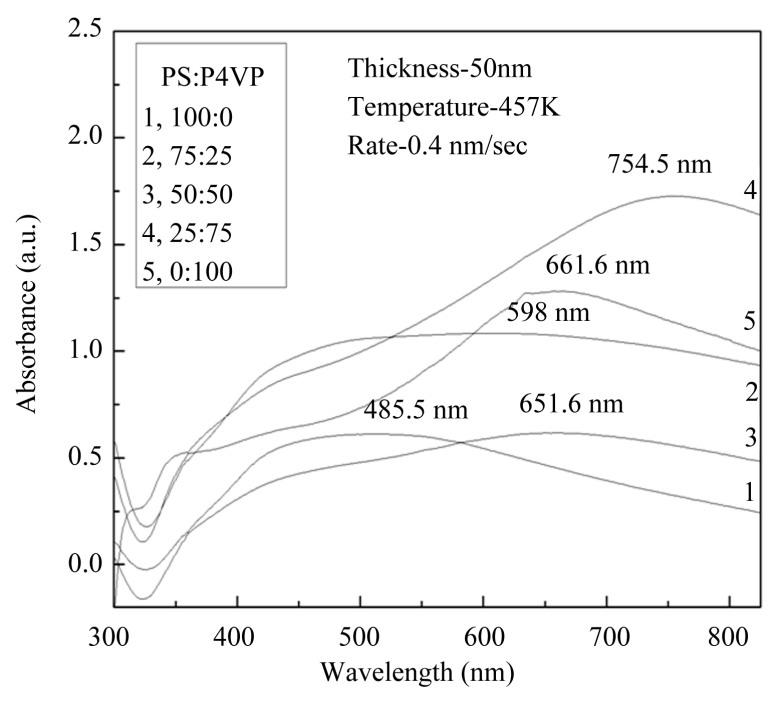

Figure 5. Optical absorption spectra for $50 \mathrm{~nm}$ silver particulate films deposited on PS/P4VP blends.

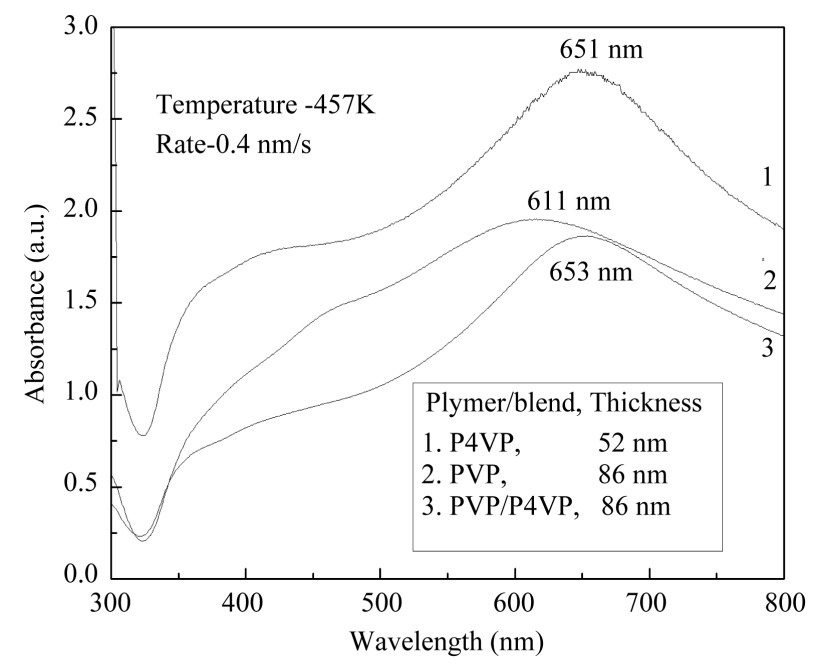

Figure 6. Optical absorption spectra for 52 \& $86 \mathrm{~nm}$ silver particulate films deposited on PVP/P4VP blends. 
(611 nm) for silver film thickness of $86 \mathrm{~nm}$. Thus, the formation of silver nanoparticles is confirmed by UV/VIS absorption spectrum of composite films [25].

\section{Conclusion}

Deposition of silver on polymer blends coated substrate held at $457 \mathrm{~K}$ provides an approach to produce stable island films with reasonable control over their electrical resistance. Higher thickness films show almost zero TCR near room temperature, a desirable property for most of the devices. Low thickness films show a negative TCR, characteristic of island film. Silver particulate films deposited on PS/PVP/P2VP/P4VP blends show better electrical properties compared to pure PS and PVP. The size distribution and dispersion of silver nanoparticles are found to be dependent on the nature of the polymer host and thickness of particulate films. With the addition of P4VP, P2VP and amount of silver, morphology of the silver particulate films on PS/P2VP (50:50), PS/P4VP (50:50, 75:25) and PVP/P4VP (50:50) could be modified to give the desired electrical results. It is an approach towards obtaining low cost, stable thin silver films on polymer composites for device applications.

\section{Acknowledgements}

The author thanks DST for the XRD and NCL (Pune) for SEM facility. The author thanks DST for the funding through Women Scientist Scheme (WOS).

\section{References}

[1] Yonzon, C.R., Stuart, D.A., Zhang, X., Mcfarland, A.D., Haynes, C.L. and Duyne, R.P.V. (2005) Towards Advanced Chemical and Biological Nanosensors-An Overview. Talanta, 67, 438-448. http://dx.doi.org/10.1016/j.talanta.2005.06.039

[2] Son, W., et al. (2004) Preparation of Antimicrobial Ultrafine Cellulose Acetate Fibers with Silver Nanoparticles. Macromolecular Rapid Communications, 25, 1632-1637. http://dx.doi.org/10.1002/marc.200400323

[3] Doty, R.C., et al. (2005) Stabilization and Functionalization of Metallic Nanoparticles. Chemistry of Materials, 17, 4630-4635. http://dx.doi.org/10.1021/cm0508017

[4] Heilmann, A. (2002) Polymer Films with Embedded Metal Nanoparticles. Springler, Berlin.

[5] Mayer, A.B.R. (2001) Colloidal Metal Nanoparticles Dispersed in Amphiphilic Polymers. Polymers for Advanced Technologies, 12, 96-106. http://dx.doi.org/10.1002/1099-1581(200101/02)12:1/2<96::AID-PAT943>3.0.CO;2-G

[6] Beecroft, L.L. (1997) Nanocomposite Materials for Optical Applications. Chemistry of Materials, 9, 1302-1317. http://dx.doi.org/10.1021/cm960441a

[7] Caseri, W. (2000) Nanocomposites of Polymers and Metals or Semiconductors: Historical Background and Optical Properties Macromol. Rapid Communications, 21, 705-722. http://dx.doi.org/10.1002/1521-3927(20000701)21:11<705::AID-MARC705>3.0.CO;2-3

[8] Eilers, H., Biswas, A., Pounds, T.D. and Norton, M.G. (2006) Teflon AF/Ag Nanocomposites with Tailored Optical Properties. Journal of Materials Research, 21, 2168-2171. http://dx.doi.org/10.1557/jmr.2006.0267

[9] Wang, Y., Li, Y., Yang, S., Zhang, G., An, D., Wang, C., Yang, Q., Chen, X., Jing, X. and Wei, Y. (2006) A Convenient Route to Polyvinyl Pyrrolidone/Silver Nanocomposite by Electrospinning. Nanotechnology, 17, 3304-3307. http://dx.doi.org/10.1088/0957-4484/17/13/037

[10] Bronstein, L.M., Sidorov, S.N. and Valetsky, P.M. (2004) Nanostructured Polymeric Systems as Nanoreactors for Nanoparticle Formation. Russian Chemical Reviews, 73, 501-515. http://dx.doi.org/10.1070/RC2004v073n05ABEH000782

[11] Wang, X., Zuo, J., Keil, P. and Grundmeier, G. (2007) Comparing the Growth of PVD Silver Nanoparticles on Ultra Thin Fluorocarbon Plasma Polymer Films and Self-Assembled Fluoroalkyl Silane Monolayers. Nanotechnology, 18, 265303-265313. http://dx.doi.org/10.1088/0957-4484/18/26/265303

[12] Kunz, M.S., Shull, K.R. and Kellock, A.J. (1992) Morphologies of Discontinuous Gold Films on Amorphous Polymer Substrates. Journal of Applied Physics, 72, 4458-4460. http://dx.doi.org/10.1063/1.352362

[13] Rao, K.M., Pattabi, M., Sainkar, S.R., Lobo, A., Kulkarni, S.K., Uchil, J. and Sastry, M.S. (1999) Preparation and Characterization of Silver Particulate Structure Deposited on Softened Poly(4-vinylpyridine) Substrate. Journal of Physics D: Applied Physics, 32, 2327-2336. http://dx.doi.org/10.1088/0022-3727/32/18/303

[14] Rao, K.M. and Pattabi, M. (2001) Effect of Polymer-Metal Particle Interaction on the Structure of Particulate Silver Films Formed on Softened Polymer Substrates. Journal of New Materials for Electrochemical Systems, 4, 11-15. 
[15] Parashar, P. (2012) Electrical Behaviour of Discontinuous Silver Films Deposited on Compatible Polystyrene/Poly(2vinylpyridine) Composite. Journal of Materials Science: Materials in Electronics, 23, 468-473. http://dx.doi.org/10.1007/s10854-011-0418-6

[16] Hassell, T., Yoda, S., Howdle, S.M. and Brown, P.D. (2006) Microstructural Characterization of Silver/Polymer Nanocomposites Prepared Using Supercritical Carbon Dioxide. Journal of Physics: Conference Series, 26, 276-279.

[17] Parashar, P. (2012) Structural Properties of Silver Particulate Films Deposited on Softened Polymer Blends of Polystyrene/Poly (2-vinylpyridine). Journal of Materials Science: Materials in Electronics, 23, 1169-1173. http://dx.doi.org/10.1007/s10854-011-0567-7

[18] Parashar, P., Ramakrishna, K., Ramaprasad, A.T. (2011) A Study on Compatibility of Polymer Blends of Polystyrene/Poly(4-vinylpyridine). Journal of Applied Polymer Science, 12, 1729-1735. http://dx.doi.org/10.1002/app.33314

[19] Haoyan, W. and Eilers, H. (2008) Electrical Conductivity of Thin-Film Composites Containing Silver Nanoparticles Embedded in a Dielectric Fluoropolymer Matrix. Thin Solid Films, 517, 575-581. http://dx.doi.org/10.1016/j.tsf.2008.06.093

[20] Kiesow, A., Morris, J.E., Radehaus, C. and Heilmann, A. (2003) Switching Behavior of Plasma Polymer Films Containing Silver Nanoparticles. Journal of Applied Physics, 94, 6988-6990. http://dx.doi.org/10.1063/1.1622990

[21] Parashar, P., Pattabi, M. and Gurumurthy, S.C. (2009) Electrical Behaviour of Discontinuous Silver Films Deposited on Softened Polystyrene and Poly(4-vinylpyridine) Blends. Journal of Materials Science: Materials in Electronics, 20, 1182-1185. http://dx.doi.org/10.1007/s10854-008-9848-1

[22] Rao, K.M., Pattabi, M., Mayya, K.S., Sainkar, S.R. and Sastry, M.S. (1997) Preparation and Characterization of Silver Particulate Films on Softened Polystyrene Substrates. Thin Solid Films, 310, 97-101. http://dx.doi.org/10.1016/S0040-6090(97)00358-1

[23] Fritzsche, W., Porwol, H., Wiegand, A., Boronmann, S. and Khler, J.M. (1998) In-Situ Formation of Ag-Containing Nanoparticles in Thin Polymer Film. Nanostructured Materials, 10, 89-97. http://dx.doi.org/10.1016/S0965-9773(98)00023-3

[24] Akamatsu, K., Takei, S., Mizuhata, M., Kajinami, A., Deki, S., Fujii, M., Hayashi, S. and Yamamoto, K. (2000) Preparation and Characterization of Polymer Thin Films Containing Silver and Silver Sulfide Nanoparticles. Thin Solid Films, 359, 55-60. http://dx.doi.org/10.1016/S0040-6090(99)00684-7

[25] Carotenuto, G. (2001) Synthesis and Characterization of Poly( $N$-vinylpyrrolidone) Filled by Monodispersed Silver Clusters with Controlled Size. Applied Organometallic Chemistry, 15, 344-351. http://dx.doi.org/10.1002/aoc.165

[26] Kim, J.Y., Shin, D.H., Ihn, K.J. and Suh, K.D. (2003) Amphiphilic Polyurethane-co-Polystyrene Network Films Containing Silver Nanoparticles. Journal of Industrial and Engineering Chemistry, 9, 37-44.

[27] Heilmann, A., Quinten, M. and Werner, J. (1998) Optical Response of Thin Plasma-Polymer Films with Non-Spherical Silver Nanoparticles. The European Physical Journal B, 3, 455-461. http://dx.doi.org/10.1007/s100510050335

[28] Takele, H., Greve, H., Pochstein, C., Zaporojtchenko, V. and Faupel, F. (2006) Plasmonic Properties of Ag Nanoclusters in Various Polymer Matrices. Nanotechnology, 17, 3499-3505. http://dx.doi.org/10.1088/0957-4484/17/14/023

[29] Mandal, S., Arumgam, S.K., Pasricha, R. and Sastry, M. (2005) Silver Nanoparticles of Variable Morphology Synthesized in Aqueous Foams as Novel Templates. Bulletin of Materials Science, 28, 503-510. http://dx.doi.org/10.1007/BF02711244

[30] Heilmann, A., Kiesov, A., Gruner, M. and Kreibig, U. (1999) Optical and Electrical Properties of Embedded Silver Nanoparticles at Low Temperatures. Thin Solid Films, 343-344, 175-178. http://dx.doi.org/10.1016/S0040-6090(98)01599-5 
Scientific Research Publishing (SCIRP) is one of the largest Open Access journal publishers. It is currently publishing more than 200 open access, online, peer-reviewed journals covering a wide range of academic disciplines. SCIRP serves the worldwide academic communities and contributes to the progress and application of science with its publication.

Other selected journals from SCIRP are listed as below. Submit your manuscript to us via either submit@scirp.org or Online Submission Portal.
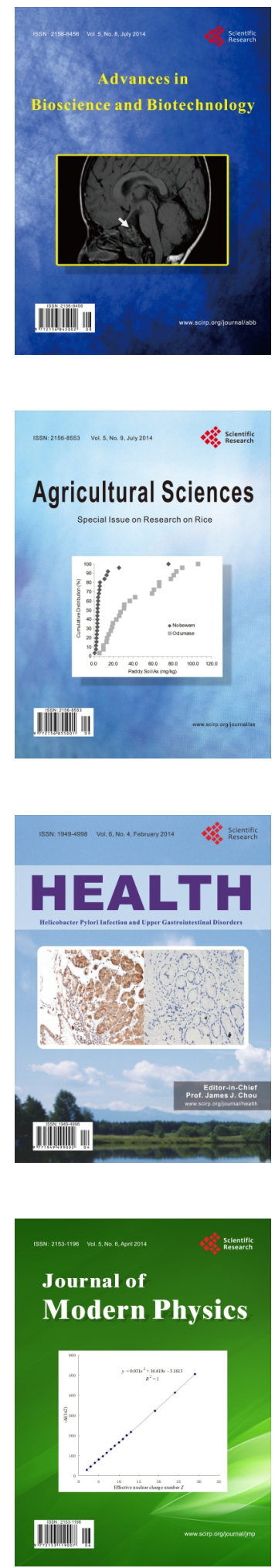
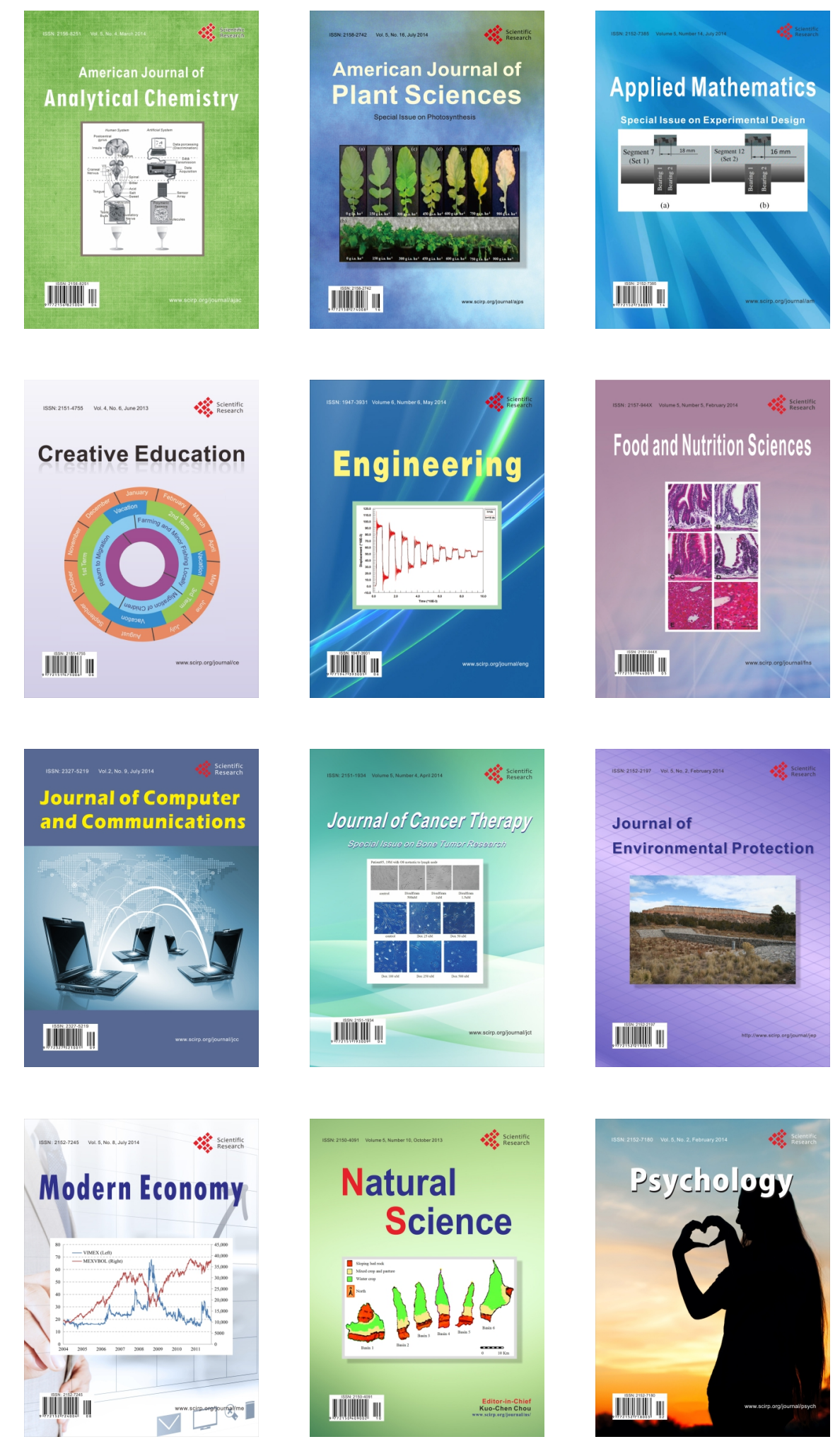